\title{
A Giant Spindle Cell Lipoma of the Parotid-Masseter Lodge (A Case Report)
}

\author{
Siham Mehdaoui Alaoui1,2*, Adbellatif Oudidi'1,2, Nawal Hammas, \\ Imane Fadlallah ${ }^{1,3}$, Mohammed Noureddine El Alami El Amine ${ }^{1,2}$ \\ ${ }^{1}$ Faculty of Medicine and Pharmacy, Sidi Mohammed Ben Abdellah University, Fez, Morocco \\ ${ }^{2}$ Department of Otorhinolaryngology, Head and Neck Surgery, Hassan II Hospital, Fez, Morocco \\ ${ }^{3}$ Department of Pathology, Hassan II Hospital, Fez, Morocco \\ Email: *siham.alaoui.m@gmail.com
}

How to cite this paper: Mehdaoui Alaoui, S., Oudidi, A., Hammas, N., Fadlallah, I. and El Alami El Amine, M.N. (2021) A Giant Spindle Cell Lipoma of the Parotid-Masseter Lodge (A Case Report). International Journal of Otolaryngology and Head \& Neck Surgery, 10, 251-257.

https://doi.org/10.4236/ijohns.2021.104023

Received: April 13, 2021

Accepted: June 29, 2021

Published: July 2, 2021

Copyright $\odot 2021$ by author(s) and Scientific Research Publishing Inc. This work is licensed under the Creative Commons Attribution International License (CC BY 4.0).

http://creativecommons.org/licenses/by/4.0/

\begin{abstract}
Background: The spindle cell lipoma is a rare benign tumor that originated from subcutaneous adipose tissue. It is a slow growing lesion and may become voluminous causing the patient an aesthetic disfigure. The diagnosis is made by the histological examination combined with immunohistochemical analysis. Radiological features present a variety of description because of the proportions difference of spindle cell lipoma components, but imaging is useful to determine the mass extents. The treatment of this kind of benign tumors is surgery which must be completed without need for other therapy. Aim: This case report highlights the exceptional location of spindle cell lipoma in the soft tissues of the parotid-masseter lodge, which may raise differential diagnosis problems with a primary parotid gland tumor. Case Presentation: A 58-year-old man, with no medical history, was presenting a swelling of the parotid region, growing progressively for 6 years, without other associated sign. The patient benefited from a careful physical examination. A computed tomography and magnetic resonance imaging were carried out. Clinical and radiological findings were suggesting a benign tumor occupying the left parotid-masseter lodge. The patient went through a surgical excision of the tumor. Histological and immunohistochemical features revealed a classic shape of spindle cell lipoma. After one year of follow-up, we notice a good recovery without local recurrence. Conclusion: Surgeons and pathologists have to keep in mind the possible development of spindle cell lipoma in any subcutaneous site even if unusual one.
\end{abstract}

\section{Keywords}

Spindle Cell Lipoma, Parotid-Masseter Lodge, Surgery, Histology 


\section{Introduction}

The spindle cell lipoma is a rare benign tumour, and usually occurs in men aged 40 70 years. It grows slowly from subcutaneous adipose tissue of posterior neck, shoulders and the upper back [1] [2], and it is exceptionally located at the soft tissues of the parotid-masseter lodge. Clinically, it is a subcutaneous tumor, solitary and painless, firmer than classic lipoma, spherical or oval, mobile, well-circumscribed and enclosed by a thin fibrous capsule [1] [3]. Histologically, two main components compose spindle cell lipoma: mature fat and bland-looking spindle cells, which may be present in different proportions [4]. Consequently, these different proportions of fat and fibrous tissue generate a considerable variety of radiological features of this lesion [5].

Spindle cell lipoma is cured by complete surgical excision, without need for other therapy. The clue for diagnosis of spindle cell lipoma is histological and immunohistochemical examination of the removed tumor, although, preoperative fine needle aspiration biopsy may suggest spindle cell lipoma diagnosis by the presence of bland spindle cells admixed with mature adipose cells in a myxoid background on cytological samples [5]. We report a case of an unusual location of a huge spindle cell lipoma in the parotid-masseter lodge, in order to make surgeons and pathologists aware of this entity to avoid confusion with other parotid and peri-parotid lesions.

\section{Case Report}

A 58-year-old man, with no medical history, presented to our department complaining of a swelling of the left parotid region, that was going on for 6 years and the swelling was progressively growing, with no other associated signs. Physical examination revealed a soft mass of the left parotid-masseter lodge, mobile, painless, with regular outlines, measuring $16 \times 10 \mathrm{~cm}$ responsible for face deformity and the overlying skin was normal. There was neither facial nerve palsy nor cervical lymphadenopathy (Figure 1).

At first, computed tomography was carried out with contrast-enhancing, and it identified an oval mass adjacent to superficial lobe of the left parotid gland, well circumscribed, hypodense, with heterogeneous contrast and focal fatty areas, without bone erosion. For further diagnosis approach, magnetic resonance imaging was performed and described a voluminous mass of the left parotid-masseter lodge, measuring $138 \times 120 \times 74 \mathrm{~mm}$, with heterogeneous signal, showing fatty and hemorrhagic areas, the mass was closely adjacent to masseter muscle and soft tissues of the cheek, and pushed the parotid gland inside and back (Figure 2).

The surgical procedure consisted of a total removal of the tumor allowed by a Redon incision. The mass depended on the soft tissues adjacent to the parotid gland from which it was easily cleavable. The tumor excision was combined with a reduction of the skin excess. The postoperative follow-up was marked by the occurrence of a hematoma into surgical site, due to the importance of the residual 

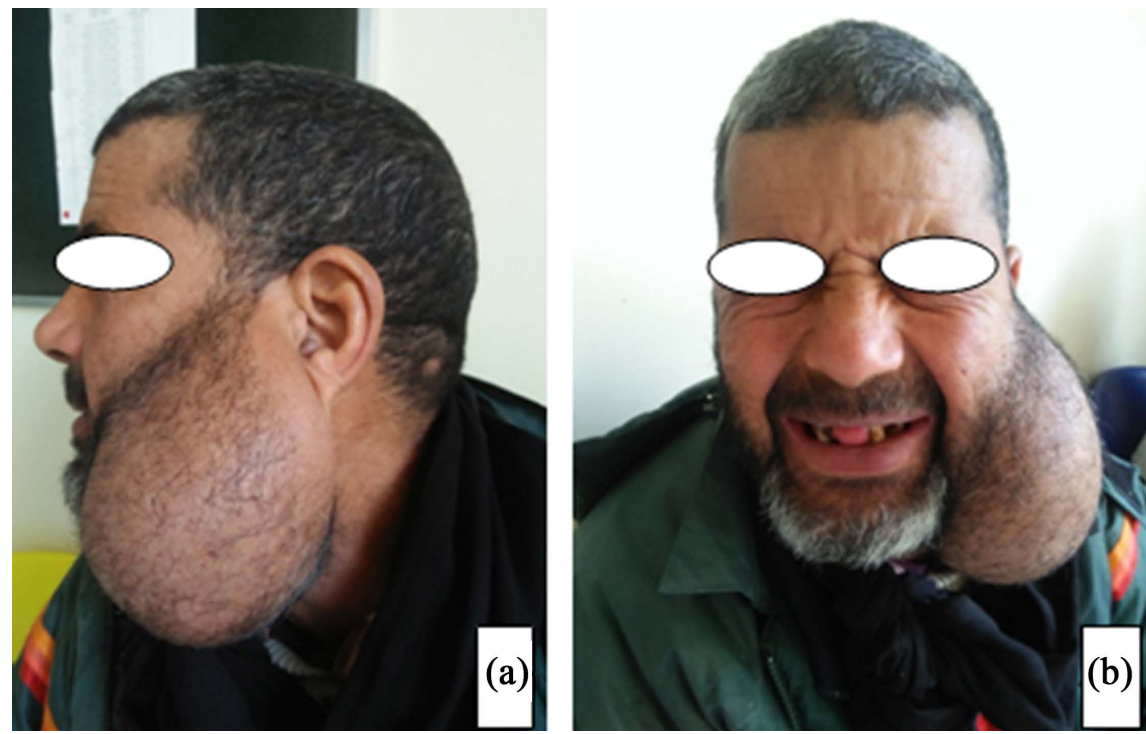

Figure 1. Clinical view showing the huge swelling of the left parotid-masseter region (a) with no facial nerve palsy (b).
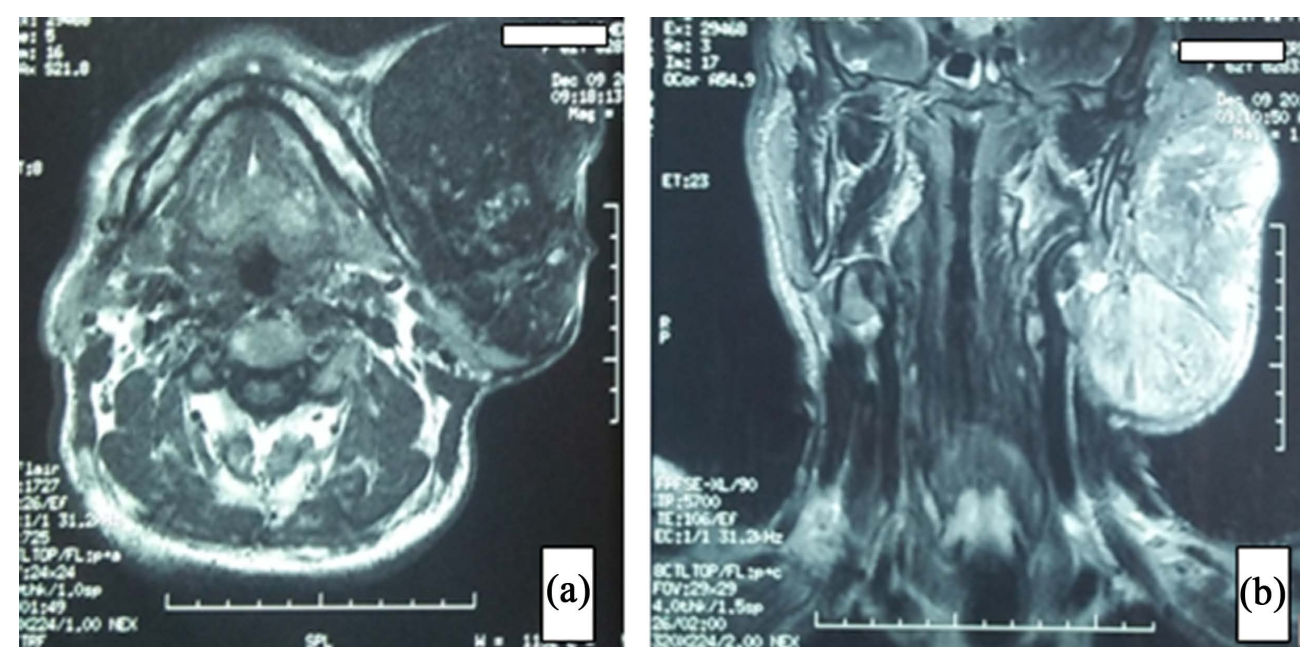

Figure 2. Magnetic resonance axial T1 (a) and coronal T2-weighted (b) images showing a voluminous mass of the parotid-masseter lodge with heterogeneous signal.

cavity, which was progressively absorbed after two punctures and compressive bandage.

Macroscopically, the removed mass was encapsulated, soft, homogenous, beige with some yellowish areas and measuring $15 \times 8 \times 5 \mathrm{~cm}$. Histological examination of the mass showed a benign mesenchymal tumor presenting uniform, mature adipocytes with fibrotic areas composed of bland-looking short spindle cells and collagen fibers without nuclear atypia. Immunohistochemical study revealed a positive immunostaining for CD34 and negative staining for S-100 protein, STAT6 and CD31, suggesting a spindle cell lipoma (Figure 3).

During one year of postoperative follow-up, no local recurrence was noticed. The patient progressed well and he was satisfied with recovery of the normal shape of his face (Figure 4). 

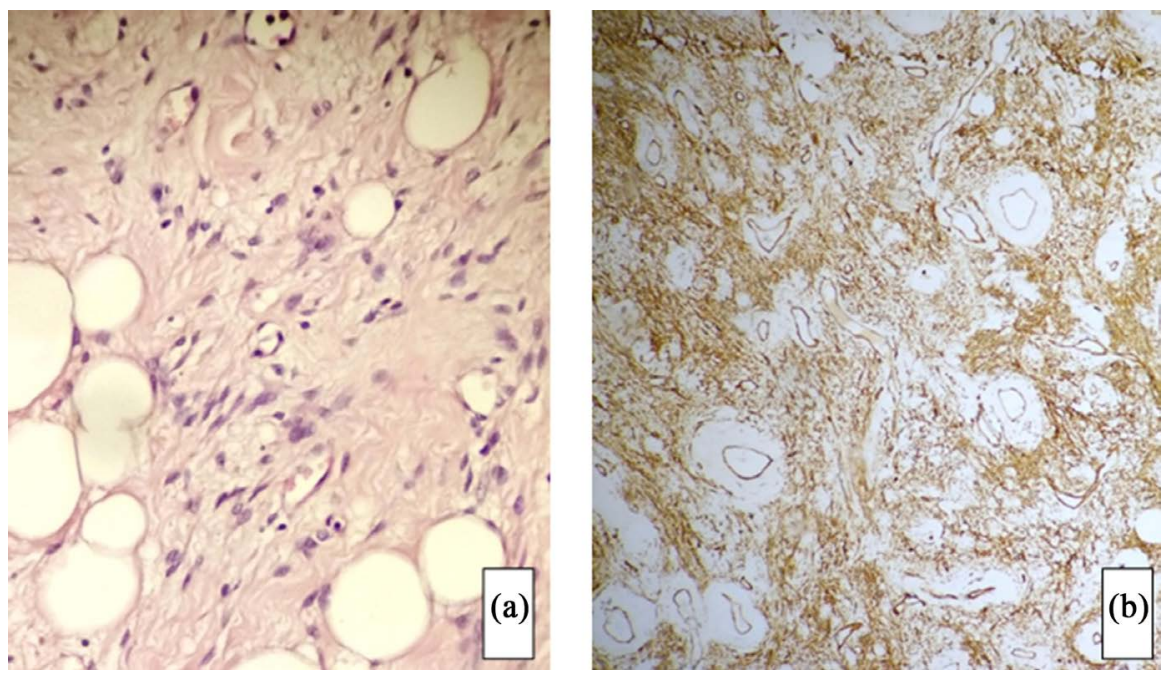

Figure 3. (a) Higher magnification of the tumor showing uniform, mature adipocytes with fibrotic areas composed of bland-looking short spindle cells and collagen fibers without nuclear atypia (HES $\times 200$ ); (b) Immunohistochemical analysis: spindle cells were diffusely stained with CD34 $(\times 100)$.

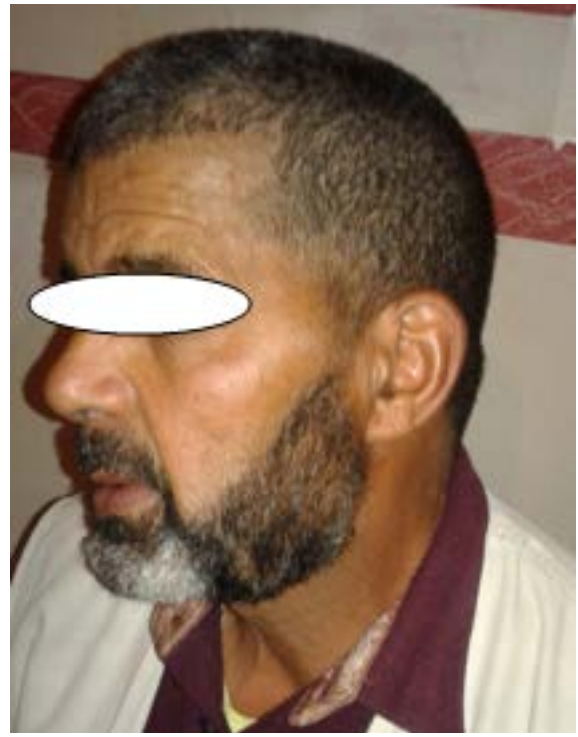

Figure 4. Clinical view after one year of postoperative follow-up.

\section{Discussion}

Spindle cell lipoma, a histological variant of lipoma, is developed from subcutaneous adipose layer and is characterized by mature adipocytes and small uniform spindle cells [1]. The first description of this pathological entity was evoked by Enzinger and Harvey in 1975 [2]. It accounts for 1.5\% of all lipomatous tumors, with a low rate of local recurrence and no risk of malignant dedifferentiation [6]. This benign tumor usually occurs in men aged 40 - 70 years and is frequently arising from the upper back, posterior neck, and shoulders [7]. However, the location in the parotid region is very exceptional and is reported in few cases in literature: Fasig reported a case of spindle cell lipoma of the parotid region in a 
47-year-old man, the tumor was suspected after fine needle aspiration of a mass of cheek [8]. Rosenthal reported a spindle cell lipoma of the left parotid gland [9]. Pujani described also a spindle cell lipoma in the parotid region in a 55-year-old man, without any attachment to the parotid gland. In this case, fine needle aspiration biopsy guided the diagnosis [6]. D'Antonio et al. described cytological features suggesting spindle cell lipoma of a primary intraparotideal mesenchymal neoplasm in a 44-year-old man [5]. Amore reported a case of spindle cell lipoma arising as a nodular mass in right peri-parotid soft tissues of a 66-years-old man, diagnosed after surgical excision without preoperative cytological study [4]. In all of these cases, the diagnosis of spindle cell lipoma was definitively confirmed by histological and immunohistochemical findings.

In fact, cytological features observed in Fine Needle Aspiration Biopsy may suggest such benign mesenchymal tumor, it showed a mixture of uniform spindle cells, mature adipocytes and collagen fibers in different proportions [6]. Although, differential diagnosis in fine needle aspiration of spindle cell lipoma can be difficult, because spindle cell lipoma shares some features with other fatty/spindle cell or myxoid lesions, benign as well as malignant: with a predominance of spindle cells, differential diagnosis includes neurilemmoma, nodular fasciitis and fibromatosis. A prominent myxoid component may evoke myxoma, myxoid neurofibroma, and myxoid liposarcoma. Though, an extensive adipocytic component must not include lipoblasts to rule out liposarcoma [5] [6] [10].

Histologically, spindle cell lipoma is well-encapsulated and consists of mature adipocytes, uniform spindle cells, thick bundles of collagen fibers within a myxoid stroma, with no mitotic figures or nuclear atypia [11]. In fact, the components of spindle cell lipoma can vary in proportion, therefore, many variants of this benign tumor are described: classic, low-fat/fat-free, fat-rich, pleomorphic, myxoid and pseudo-angiomatous [12] [13]. Immunohistochemical study is paramount to establish the right diagnosis, the staining of CD34 and Vimentin is strongly positive, S-100 protein-STAT6-CD31 staining is negative, however, Chen et al. reported some unexpected cases of spindle cell lipoma showing positive staining of S-100 protein, which was less common [12].

On radiological imaging, making diagnosis is so difficult because of the various spectrum of imaging features produced by the ratio variation between fat and spindle cells, with fat-free or low-fat lesions [1]. Even though magnetic resonance imaging gives more details about soft tissues characteristics, it may show different appearance: from non-fatty and heterogeneous to lipoma-like, thereby it couldn't establish a specific diagnosis, but it may be helpful to evaluate the extent of the tumor, which is so important for surgeons before surgical approach of dangerous anatomical regions [10].

The treatment of spindle cell lipoma is surgical excision, that must be totally performed, without need for complementary therapy [4] [7] [14]. In general, the tumor is easily removed from subcutaneous tissue, so, the surgical management is carried out for the following reasons: aesthetics when there is compression of 
neighbouring anatomical structures; and when the tumor presented characteristics consistent with a malignant tumor (rapid growth or invasion into nerve/bone), including those that are deep located and $>5 \mathrm{~cm}$ in diameter [3]. As reported by several authors, the post operative follow-up reveals no local recurrence and the healing is uneventful [1] [3] [5] [7] [14].

\section{Conclusion}

Even if the spindle cell lipoma is a benign tumor, it may be responsible for an ugly appearance for patient due to its voluminous size. As described in our case, this lesion may raise preoperative differential diagnostic problems with a primary parotid gland tumor. After complete surgical excision, the local recurrence is absent: it permits to consider surgery as a curative management for this kind of tumor.

\section{Consent}

Consent from the patient was obtained for publication.

\section{Conflicts of Interest}

The authors declare no conflicts of interest regarding the publication of this paper.

\section{References}

[1] Seo, B.F., Kang, I.S. and Oh, D.Y. (2014) Spindle Cell Lipoma: A Rare, Misunderstood Entity. Archives of Craniofacial Surgery, 15, 102-104. https://doi.org/10.7181/acfs.2014.15.2.102

[2] Enzinger, F.M. and Harvey, D.A. (1975) Spindle Cell Lipoma. Cancer, 36, 852-859. https://doi.org/10.1002/1097-0142(197511)36:5<1852::AID-CNCR2820360542>3.0. CO;2-U

[3] Petit, D., Menei, P. and Fournier, H.-D. (2011) An Unusual and Spectacular Case of Spindle Cell Lipoma of the Posterior Neck Invading the Spinal Cervical Canal and Posterior Cranial Fossa: Case Report. Journal of Neurosurgery: Spine, 15, 502-506. https://doi.org/10.3171/2011.7.SPINE10820

[4] Amore, F.F., Musumeci, G., Castrogiovanni, P., Longo, F.R. and Magro, G. (2015) Spindle Cell Lipoma of Peri-Parotid Soft Tissues. Report of a Case and Histogenetic Considerations. Journal of Histology \& Histopathology, 2, 7. https://doi.org/10.7243/2055-091X-2-7

[5] D’Antonio, A., Baldi, C., Memoli, D., Caleo, A., Rosamilio, R. and Zeppa, P. (2013) Fine Needle Aspiration Biopsy of Intraparotid Spindle Cell Lipoma: A Case Report. Diagnostic Cytopathology, 41, 171-173. https://doi.org/10.1002/dc.21801

[6] Pujani, M., Agarwal, S., Nangia, A. and Lalita Jyotsna, P. (2013) Spindle Cell Lipoma Masquerading as Lipomatous Pleomorphic Adenoma: A Diagnostic Dilemma on Fine Needle Aspiration Cytology. Journal of Cytology, 30, 55. https://doi.org/10.4103/0970-9371.107516

[7] Machol, J.A., Cusic, J.G., O’Connor, E.A., Sanger, J.R. and Matloub, H.S. (2015) Spindle Cell Lipoma of the Neck: Review of the Literature and Case Report. Plastic and Reconstructive Surgery-Global Open, 3, e550. 
https://www.ncbi.nlm.nih.gov/pmc/articles/PMC4727702/ https://doi.org/10.1097/GOX.0000000000000405

[8] Fasig, J.H., Robinson, R.A., McCulloch, T.M., Fletcher, M.S. and Miller, C.K. (2001) Spindle Cell Lipoma of the Parotid: Fine-Needle Aspiration and Histologic Findings. Archives of Pathology \& Laboratory Medicine, 125, 820-821. https://doi.org/10.5858/2001-125-0820-SCLOTP

[9] Rosenthal, L.S., Garzon, S., Setty, S. and Yao, M. (2006) Left-Sided Facial Mass. Spindle Cell Lipoma of the Parotid Gland. Archives of Pathology \& Laboratory Medicine, 130, 875-876. https://doi.org/10.5858/2006-130-875-LFM

[10] Domanski, H.A., Carlén, B., Jonsson, K., Mertens, F. and Akerman, M. (2001) Distinct Cytologic Features of spindle Cell Lipoma. A Cytologic-Histologic Study with Clinical, Radiologic, Electron Microscopic, and Cytogenetic Correlations. Cancer, 93, 381-389. https://doi.org/10.1002/cncr.10142

[11] Zouaidia, F. and Coindre, J.-M. (2011) Pseudoangiomatous Spindle Cell Lipoma: About Six Cases. Annales de Pathologie, 31, 242-245. https://doi.org/10.1016/j.annpat.2011.04.003

[12] Chen, S., Huang, H., He, S., Wang, W., Zhao, R., Li, L., et al. (2019) Spindle Cell Lipoma: Clinicopathologic Characterization of 40 Cases. International Journal of Clinical and Experimental Pathology, 12, 2613-2621.

[13] Ko, J.S., Daniels, B., Emanuel, P.O., Elson, P., Khachaturov, V., McKenney, J.K., et al. (2017) Spindle Cell Lipomas in Women: A Report of 53 Cases. American Journal of Surgical Pathology, 41, 1267-1274. https://doi.org/10.1097/PAS.0000000000000915

[14] Lau, S.K., Bishop, J.A. and Thompson, L.D.R. (2014) Spindle Cell Lipoma of the Tongue: A Clinicopathologic Study of 8 Cases and Review of the Literature. Head \& Neck Pathology, 9, 253-259. https://doi.org/10.1007/s12105-014-0574-0 